Slavica

bruxellensia

\section{Slavica bruxellensia}

Revue polyphonique de littérature, culture et histoire

slaves

\section{$4 \mid 2009$}

Espaces slaves / espaces belges

\title{
Eugeniusz Tkaczyszyn-Dycki, Piosenka o zależnościach i uzależnieniach
}

\section{Thibault Deleixhe}

\section{OpenEdition}

\section{Journals}

Édition électronique

URL : http://journals.openedition.org/slavica/283

DOI : 10.4000/slavica.283

ISSN : 2034-6395

\section{Éditeur}

Université libre de Bruxelles - ULB

\section{Édition imprimée}

Pagination : 67

ISSN : 2031-7654

Référence électronique

Thibault Deleixhe, « Eugeniusz Tkaczyszyn-Dycki, Piosenka o zależnościach i uzależnieniach », Slavica bruxellensia [En ligne], 4 | 2009, mis en ligne le 15 octobre 2009, consulté le 22 septembre 2020. URL http://journals.openedition.org/slavica/283 ; DOI : https://doi.org/10.4000/slavica.283

Ce document a été généré automatiquement le 22 septembre 2020.

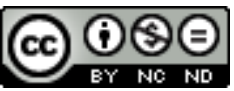

Les contenus de Slavica bruxellensia sont mis à disposition selon les termes de la Licence Creative Commons Attribution - Pas d'Utilisation Commerciale - Pas de Modification 3.0 France. 


\section{Eugeniusz Tkaczyszyn-Dycki, Piosenka o zależnościach $i$ uzależnieniach}

Thibault Deleixhe

\section{RÉFÉRENCE}

Eugeniusz Tkaczyszyn-Dycki, Piosenka o zależnościach i uzależnieniach, Wrocław, Biuro Literackie, 2008, $54 \mathrm{p}$. 
1 Le jury du prix Nike adore surprendre! Et cette année encore, il n'échappe pas à la règle. La victoire d'Eugeniusz TkaczyszynDycki, avec son recueil poétique Piosenka o zależnościach $i$ uzależnieniach (Chant de la servitude et de la dépendance), était pour le moins inattendue. Le personnage est loin d'être un inconnu du monde de la poésie polonaise contemporaine, c'est plutôt cette dernière qui, depuis quelques années, peine à se frayer un chemin jusqu'à ses lecteurs. D'où la surprise du grand public! Le comité n'a pas fait mystère $d u$ fait que l'attribution du prix Nike de cette année avait pour but de revitaliser la tradition poétique polonaise, et voulait attirer l'attention sur les

EugenNusz TracZrszYN-Drcki PLOSFXKA O ZALEZXOSCIACR I VZALEZSIEXIACR

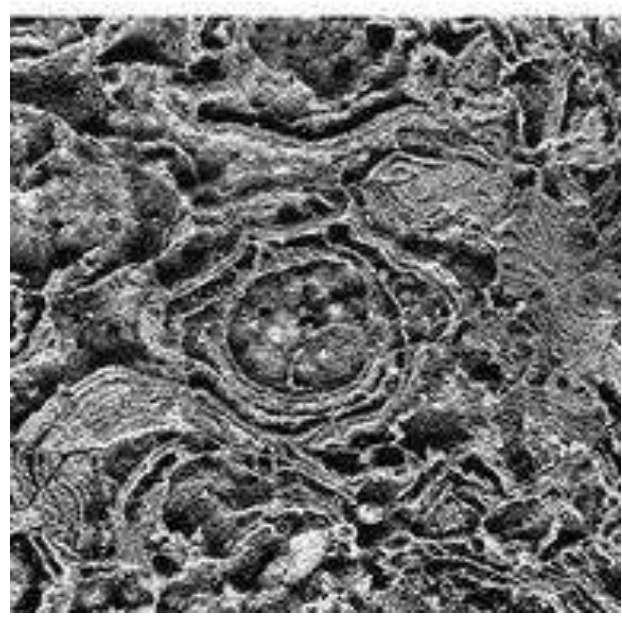
nombreux disciples de Czesław Miłosz et de Tadeusz Różewicz, une génération dont Tkaczyszyn-Dycki (né en 1962) est le brillant représentant.

2 L'ouvrage primé est un recueil finement ciselé, composé de cinquante poèmes. Ces petits fragments autobiographiques s'articulent autour de trois pôles thématiques : la mort et le processus de départ de la mère du poète, l'identité sexuelle trouble du sujet lyrique, et la vie quotidienne d'un village à proximité de la frontière ukrainienne. Le poète porte ses douleurs qui se mêlent et se répondent de poème en poème, au travers de variations et de formules qui se répètent. Les redites ne visent pas tant à expliciter le propos qu'à l'approfondir et à le complexifier, à en dresser un paysage kaléidoscopique. Elles nous plongent toujours plus avant dans un univers hanté par la mort et l'absence, qui refuse toutefois de se livrer à un pessimisme sans recours. Le lecteur est happé par ce récit épars que chaque poème résume autrement.

3 La langue de Tkaczyszyn-Dycki a la qualité exquise des voix des grands poètes, elle est identifiable entre toutes. Tkaczyszyn-Dycki s'est composé un mode d'expression propre qui oscille entre la complexité stylistique du baroque sarmate et la banalité du phrasé quotidien. Une langue qui mêle la considération métaphysique aux vociférations de l'usager du bus, l'épitaphe à l'anecdote Cet idiome qui conjugue le marinisme de Jan Andrzej Morsztyn aux accents paillards de Villon s'était trouvé un admirateur de choix en la personne de Miłosz, qui décerna par deux fois son prix littéraire personnel à Tkaczyszyn-Dycki.

4 Si l'objectif du comité Nike était de médiatiser la poésie actuelle, alors TkaczyszynDycki réunit effectivement les qualités nécessaires : son œuvre est faussement simple. Dans un premier temps, elle semble se laisser lire sans résistance. En ce sens, sa lecture s'apparente à une promenade dans un jardin anglais, on déambule dans des décors familiers quoiqu'en empruntant à chaque poème un chemin différent. Mais c'est une simplicité de façade! Si l'on prend le temps de se perdre dans ce jardin broussailleux, on en saisit la nature volatile et éphémère, ce qui nous paraissait une végétation épaisse se révèle un buisson croupissant, un taillis torturé. Tout le parc est marqué du sceau subtil de la dégradation permanente. L'accent est mis sur l'omniprésence d'une 
mort proche qui assure à la poésie de Tkaczyszyn-Dycki sa portée métaphysique universelle et touche à l'humain en chaque lecteur. Une expérience forte qui contrairement à l'idée que l'on se fait du morbide - libère de l'angoisse plus qu'elle n'y incline. Un recueil à recommander, donc, à tous ceux qui ne se savent pas éternels et tâchent de se réconcilier avec leurs craintes.

INDEX

Index géographique: Pologne

Index chronologique : XXe siècle

Mots-clés : littérature polonaise, NIKE

\section{AUTEURS}

\section{THIBAULT DELEIXHE}

Étudiant à l'Université Libre de Bruxelles en Langues et Littératures modernes, orientation slaves 